Journal of Machine Engineering, 2020, Vol. 20, No. 3, 95-105

ISSN 1895-7595 (Print) ISSN 2391-8071 (Online)

Received: 27 November 2019 / Accepted: 13 March 2020 / Published online: 25 September 2020

process monitoring, tool wear, polar figures

\author{
Sven GOETZ ${ }^{1 *}$ \\ Daniel SCHRAKNEPPER ${ }^{1}$ \\ Gabriel FAUSTINI ${ }^{1}$ \\ Thomas BERGS ${ }^{1}$
}

\title{
PROCESS MONITORING IN END MILLING USING POLAR FIGURES
}

\begin{abstract}
Knowledge of the tool wear state in machining has become an important issue in research and industrial application. Current systems use the spindle power or cutting force as measured variable and refer it to a taught set point. However, this method lacks the ability to adapt to new work piece geometries. A new approach focusses on the tool instead of the work piece, and uses a sensory tool holder with integrated strain gauges. This tool holder provides polar figures whose shapes relate to the engagement conditions and whose area is a function of the tool load. As the tool load increases with tool wear, the area of the polar figures provides information about the tool wear status, and with knowledge about the engagement conditions, the model can be calibrated.
\end{abstract}

\section{INTRODUCTION}

\subsection{STATE OF THE ART}

Milling is a separating process according to DIN 8580, where the separation takes place during the chip formation process [1]. When the blade enters the workpiece, it causes elastic and plastic deformation and the flank face of the tool causes friction with the work piece surface [2]. Those effects cause forces and heat that lead to high temperatures in the cutting zone. The combination of high temperatures and high mechanical stresses cause a decay of the tool, denoted as tool wear [3]. The ISO3685 classifies tool wear into three groups, which are crater wear, abrasive wear and cracks. These lead to a change in the micro-geometry of the tool and increase the cutting force and thus the temperatures $[4,5]$. These effects may inflict insufficient geometrical accuracy of the product or lead to catastrophic failure of the tool. As tool wear is an inevitable effect in machining, there are efforts to measure the tool wear during the cutting process. Classical process monitoring uses envelopes of the respective

\footnotetext{
${ }^{1}$ WZL der RWTH Aachen, Aachen, Germany

*E-mail: S.Goetz@wzl.rwth-aachen.de https://doi.org/10.36897/jme/119690
} 
signal for a stable process with new tools and compares each consecutive signal to this reference [6]. While this is suitable for industrial serial production, it is not robust to changes of the process [7]. Recent research has focussed on developing systems that allow tool wear monitoring for small batch sizes down to single item production [8]. These can be classified into two basic approaches: Finding features that are independent of the cutting engagement or using a digital twin of the process to simulate an expected signal. Keaver calculates the variance of the torque-generating current of the feed drives and relates it to the position data to determine the tool wear [9]. Similar methods are being developed over the past 10 years at the Universiti Kebangsaan Malaysia from various researchers. They use the standard deviation of a force signal and its higher-order statistical measures (skewness and kurtosis) to calculate a tool wear indicator [10-13]. Fussel et al. also use the force signal to calculate the coefficients of a force model. Their approach use the hypothesis of Cui that states that the tangential force component in milling is independent on the engagement angle $[14,15]$. Newer approaches use a multi-sensory approach. Zhou et al. use five different sensors to create eight time-domain and seven frequency-domain features that are combined into one global feature which correlates with tool wear [16]. Apart from those feature-based approaches, other research uses models to predict an expected force or power signal. Researchers from the University of Hannover have shown various research papers within the scope of the collaborate research centre „SFB 653: Gentelligent Components in their Lifecycle" and extended it [17]. They build on a material removal model and a force model to calculate the expected force signal during the machining process for a new tool. This signal can then be compared to the online-measured force signal of the real cutting process $[7,18,19$,$] . Sheng published another, similar approach that also uses an engagement model$ and an Altintas force model to predict the expected force signal in 3-axis ball end milling [20].

The online estimation of the engagement conditions in milling has been subject to research since 1987. Altintas and Yellowley showed an approach that uses a piezoelectric dynamometer to calculate the ratio between the $\mathrm{x}$ - and $\mathrm{y}$-component of the cutting force in straight cuts, which they refer to the width of cut in a regression model for inserted tooth milling [21]. Tarn and Tomizuka urther improved this system in 1989 [22]. Researchers of the University of Seoul showed a new approach in the early noughties. Kwon and Choi use the ratio of the derivatives of the radial and tangential cutting force to estimate the width of cut [23]. Hwang improves this system by taking into account the force drop when an insert leaves material contact [24]. While these approaches use the magnitude of the cutting force or changes of it, Choi and Yang show an approach that recognizes patterns in the force signal [25]. They use the maximum and minimum of the cutting force, obtained by the deriving the signal, and relate these points to the depths of cut. In a second step, and with prior knowledge of the depth of cut, they estimate the immersion angle to obtain the width of cut.

A more recent approach shown by Bergs and Goetz uses the bending moments in two perpendicular directions of the tool coordinate system to plot two-dimensional figures that correspond to the engagement conditions [26]. They use the points of maximum curvature of these figures to train an artificial neural network that estimates the current width of cut. The system is capable of identifying the width of cut with high accuracy for a wide range of widths of cut. 


\subsection{RESEARCH AIM AND APPROACH}

The feature-based approaches presented above share in common the lack of adaptability. They need calibration and teaching to determine the model parameters, and most rely on sensors that are not applicable in industrial environment. Simulation-based approaches need less to no calibration, but require sophisticated synchronization between the simulation data and the measurement data. Furthermore, the required simulations create high computational effort. There exists no system that is capable of judging the current tool wear status in milling with no prior knowledge of the workpiece. The aim of the current research is hence to provide a new approach to deliver a tool wear monitoring system in end milling that estimates tool wear without prior knowledge of the geometry of the workpiece or the engagement conditions. This system relies on a sensory tool holder with integrated strain gauges that delivers characteristic polar figures derived from the bending moments of the tool holder. These polar figures can be used to determine the engagement conditions [26]. The engagement conditions determine the chip thickness and width of chip, thus having a significant influence on the cutting force. With knowledge of the bending moment of the tool holder and the respective engagement conditions, the relative increase of bending moment of a specific engagement condition that is related to tool wear can be determined. The following research shows the algorithm for the determination of the engagement conditions (Chapter 2) and the development of a tool wear model (Chapter 3). Chapter 4 shows their combination and a system that is capable to estimate tool wear without prior knowledge of the engagement conditions.

\section{DETERMINATION OF THE ENGAGEMENT CONDITIONS}

Tool wear can be monitored online by measuring the force or any force-related signal (spindle power, feed drive power or bending of the tool holder), as it results in a change of the cutting force [27]. However, a change of the depth or width of cut also incurs a change of the cutting force, superimposing the effect of tool wear. Therefore, a monitoring system for the small batch production, down to lot size one, requires knowledge of the engagement conditions, as only force information from similar process situations may be compared to estimate the tool wear. Approaches to determine the width of cut have been shown over the past 30 years [21-25]. However, these systems rely on piezoelectric dynamometers and have mostly been shown for laboratory conditions only. A new method that uses strain gauges which are integrated into a sensory tool holder has been shown by Bergs and Goetz and was used for the current research [26]. The following Chapter 2.1 will outline the analytical relationship between the polar figures obtained by the sensory tool holder and the engagement conditions of the end milling process. Chapter 2.2 shows the identification algorithms based on [26].

\subsection{ANALYTICAL MODEL DESCRIPTION}

The sensory tool holder Spike ${ }^{\circledR}$ is capable of measuring the bending moments $M_{x}$ and $M_{y}$ of the tool holder, which are the result to the cutting force, in the two perpendicular 
directions $X$ and $Y$ that span the cutting plane. A polar figure is the interpretation of these two signals in a Cartesian coordinate system that rotates synchronous with the tool, as shown in Fig. 1. For each discrete point of time t, the respective values for $M_{x}$ and $M_{y}$ are drawn in the coordinate system. After one full rotation of the tool, the same cutting conditions occur again, reaching the same $M_{x} / M_{y}$ combination. This results in a repetitive pattern, called polar figure.

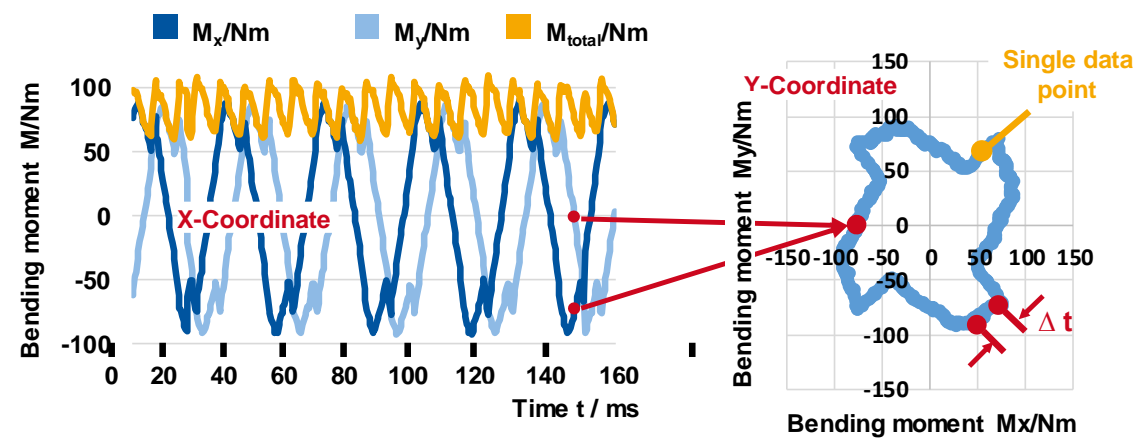

Fig. 1. Transformation of time-domain signal into polar figures

While time-domain signals contain a time information, this information is partially lost in polar figures. Provided the cutting conditions do not change significantly during one tool rotation, the data points that form the polar figure evolve along a fixed pattern to form a closed loop. Any information obtained from this pattern can be regarded in analogy to a short-time frequency analysis, when a sequence of polar figures is being analysed [28]. The shape of the polar figure is strongly related to the geometry of the tool and the engagement conditions of the milling process, i.e. the width and depth of cut [26]. It is therefore possible to monitor the current engagement conditions of a milling process based on the polar figures. Figure 2 (left) shows the polar figures of a milling process with an end mill of four cutting edges, a diameter of $12 \mathrm{~mm}$ and a helix angle of $38^{\circ}$ for five different widths of cut, but the same depth of cut $a_{p}=15 \mathrm{~mm}$. The size of the polar figures increases with the width of cut due to the increase in maximum chip thickness [2].
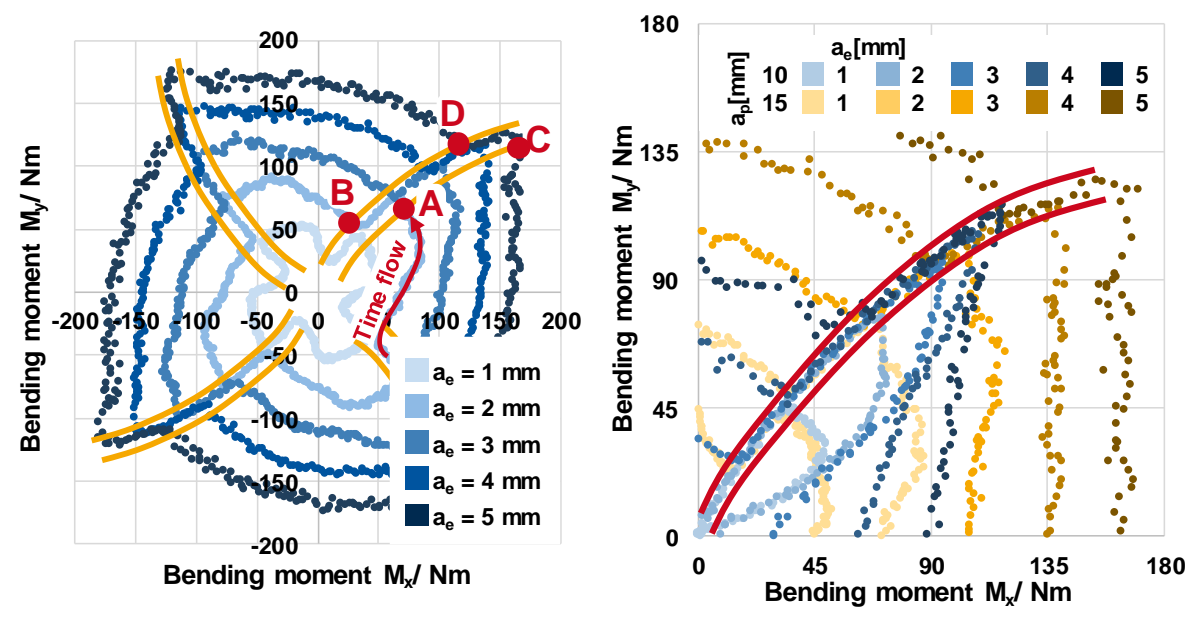

Fig. 2. Characteristic points of polar figures and derivation of the identification corridor 
The algorithm for the engagement identification detects features of the polar figures that change with the width of cut [26]. Figure 2 (left) shows four regions where the five polar figures form one common line of data points, marked in orange. This region shall be defined as "identification region". Each of these regions is formed from parts of the polar figures. Polar figures from processes with smaller width of cut $a_{e}$ contribute the parts closer to the origin and polar figures from processes with larger width of cut $a_{e}$ the parts further from it. This indicates a relationship between parts of the polar figures with their corresponding width of cut. The first point along the time flow of a polar figure (c.f. Fig. 2, left) that lies within the identification region shall be defined as entrance point, the last point inside this region as exit point. These entrance and exit points are ranked according to their respective width of cut. For example, the polar figure of $a_{e}=2 \mathrm{~mm}$ enters the identification region at point $A$ and exits it at point $B$. For $a_{e}=5 \mathrm{~mm}$, this happens at points $C$ and $D$, respectively. $C$ is considerably further from the origin than $\mathrm{A}$, and it gets apparent that the entrance points for $a_{e}=3 \mathrm{~mm}$ and $4 \mathrm{~mm}$ lie in between $A$ and $C$ along the orange line. This strongly indicates a systematic relationship between the width of cut and the entrance and exit points of a polar figure along a certain region that is defined by the mutual combination of polar figures with different widths of cut. This fact shall be used to develop a method to estimate the current width of cut from the polar figures. Figure 2 (left) shows that the identification region can be defined for a set of polar plots with the same depth of cut, but different widths of cut. It hence needs to be analysed how the identification region is influenced by the depth of cut. Figure 2 (right) shows exerts from 10 different polar plots with a depth of cut of $a_{p}=10$ and $15 \mathrm{~mm}$. The identification regions from both $a_{p}$ groups coincide with each other. This indicates that the identification region does not depend on the process parameters, but solely on the geometry of the tool. However, the entrance and exit points of polar figures of a specific width of cut lie towards larger bending moments for larger depth of cuts. The entrance and exit points can be used as input into an algorithm to detect the width of cut during the machining process. This will be shown in the following chapter.

\subsection{ALGORITHM FOR THE IDENTIFICATION OF THE ENGAGEMENT CONDITIONS}

The algorithm for the identification of the width of cut in end milling was shown in [26]. It uses an artificial neural network (ANN) to train the relationship between several input variables and an output variable, which is the width of cut $a_{e}$. The entrance and exit points, as well as the quadrant, the depth of cut and the area of the polar figure are used as input variables for the ANN. The estimation method for the width of cut relies on the entrance and exit points into and from the previously defined identification region. In order to be able to quantify this, the identification region is subdivided into percentiles according to Fig. 3 (top left). The minimum and maximum points of the region are used as reference for $0 \%$ and $100 \%$, respectively. Figure 3 (left) shows exerts of three polar figures with $a_{p}=10 \mathrm{~mm}$ and $a_{e}$ of 3 , 4 and $5 \mathrm{~mm}$. The polar figure of $a_{e}=4 \mathrm{~mm}$ exits the identification region at $35 \%$ of its maximum value (red circle). Likewise, percentages can be defined for all entrance and exit points. As can be seen in Fig. 2 (right), the entrance and exit points for the same width of cut but larger depth of cut are at a higher percentage (further away from the origin). This aspect needs to be considered in the development of the method. 

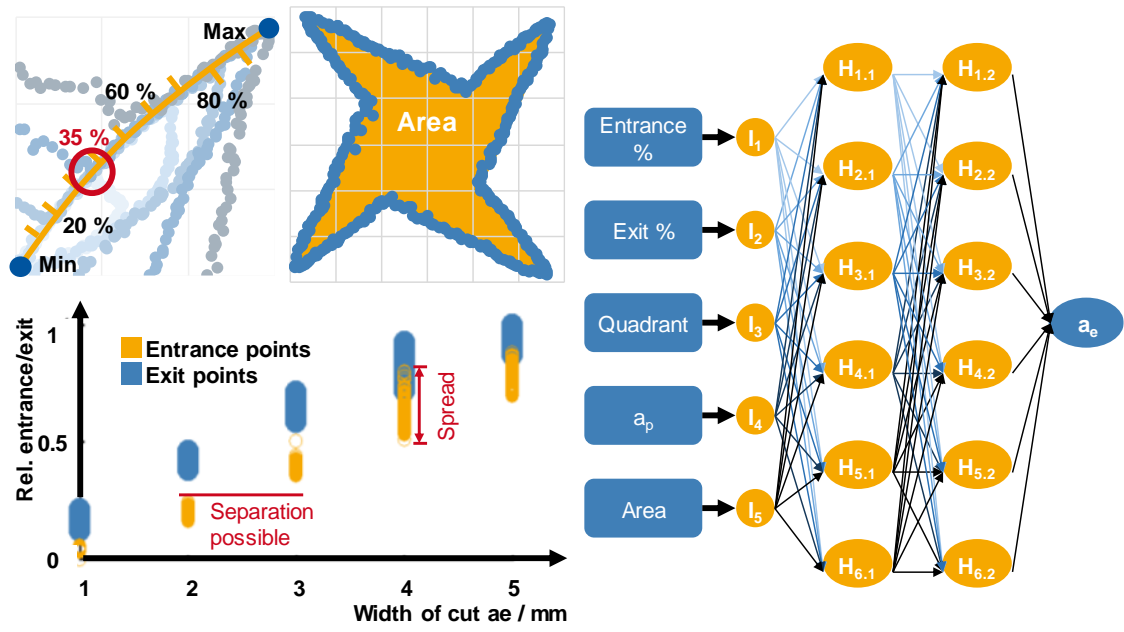

Fig. 3. Structure of the engagement conditions identification system

A second quantity describing the engagement situation is the area enclosed by the polar figure. With increasing engagement, either by a larger depth or by a larger width of cut, the load on the tool increases. As the polar figure is representing the integral load on the tool over one tool rotation, its area correlates strongly with the tool load and thus with the engagement conditions. However, the area alone is not suitable for detecting the engagement conditions, as a change of it can be induced by both the width or the depth of cut or the occurrence of tool wear. The entrance and exit points as well as the area, the depth of cut and the quadrant are used as input variables for the method.

\section{TOOL WEAR MODEL}

Tool wear experiments were conducted to develop and prove the tool wear model. The experiments were conducted on a DMG Mori NHX 5000 milling machine in the stainless steel X5CrNi18-10 (1.4301) using coated cemented carbide end mills with a radius of $r=6 \mathrm{~mm}$, a number of cutting edges $z=4$ and a helix angle of $\lambda=38^{\circ}$. The width of cut was varied continuously between $1 \mathrm{~mm}$ and $5 \mathrm{~mm}$. The depth of cut was constant at $a_{p}=8$ $\mathrm{mm}$. The feed per tooth was $f_{z}=0.03 \mathrm{~mm}$. There were three different experimental runs with varying cutting speed of $v_{c 1}=75 \mathrm{~m} / \mathrm{min}, v_{c 2}=100 \mathrm{~m} / \mathrm{min}$ and $v_{c 3}=125 \mathrm{~m} / \mathrm{min}$. The tool wear was measured every $1.5 \mathrm{~m}$ of cutting length using a light microscope Keyence VHX $900 \mathrm{~F}$. The tool life travel paths of the three trials were $l_{1}=127.5 \mathrm{~m}, l_{2}=22.5 \mathrm{~m}$ and $l_{3}=7.5 \mathrm{~m}$. Fig. 4 shows the development of the milling tool for the first series.

The tool wear was assessed by the flank wear $V B$, the threshold for abortion of the experiments was set to $V B_{\lim }=100 \mu \mathrm{m}$. During the cutting experiments, the bending moments of the tool holder were measured using a Spike ${ }^{\circledR}$ class $C$ sensory tool holder to create polar figures. These were used to determine the widths of cut and the area of the polar figures as describes in Chapter 2. After each interval of $1.5 \mathrm{~m}$ cutting length, the tool wear was measured and the average area for each of the five classes of width of cut was calculated and labeled with the respective flank wear. The area values of the first set, with a new tool, were taken as 
a reference for the further measurements. For each consecutive measurement, the ratio between its area and the reference area was calculated. Figure 5 shows the development of these ratios for all five widths of cut.
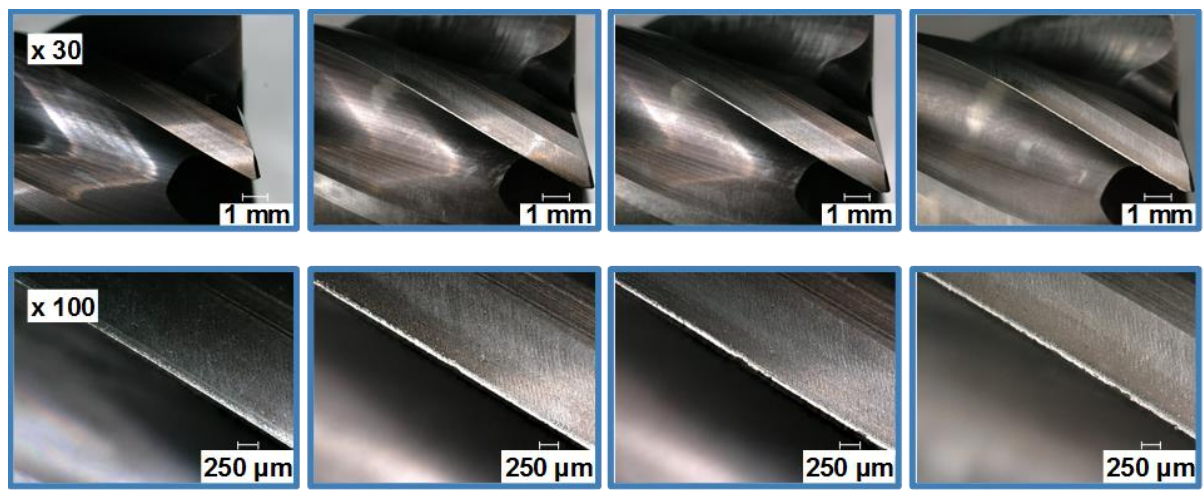

Fig. 4. Tool wear development for end milling tool, $v_{c}=75 \mathrm{~m} / \mathrm{min}$
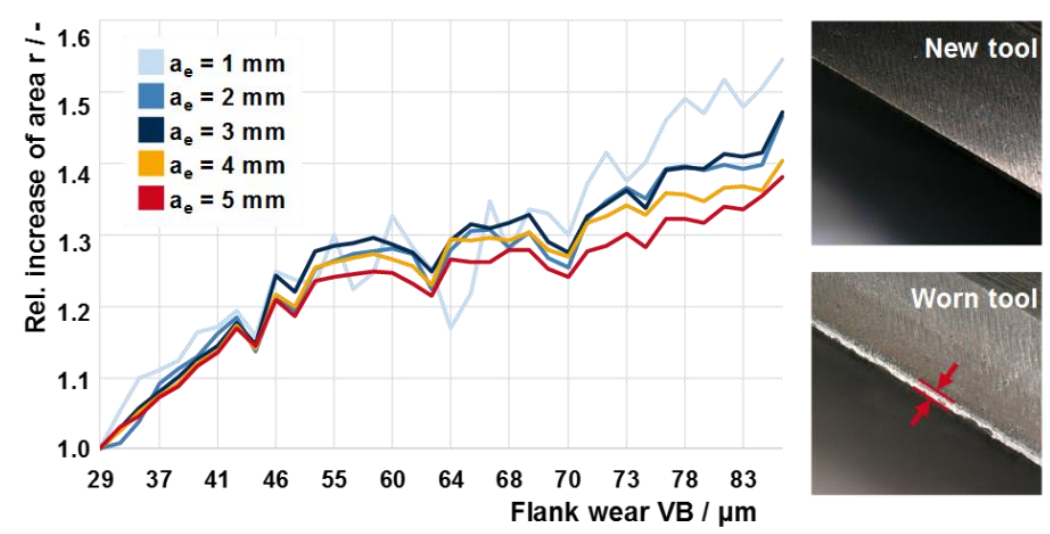

Fig. 5. Progression of relative increase of polar figure area with tool wear development, $v_{c}=75 \mathrm{~m} / \mathrm{min}$

All five curves show a similar, S-shaped increase with the flank wear. It is noticeable that the increase is stronger for smaller chip thicknesses. Fussel and Cui state that flank wear results in a change of the tangential cutting coefficient $m_{c t}$, according to the Kienzle force model $[14,15]$. As $m_{c t}$ is always smaller than 1 , its effect is larger for smaller chip thicknesses due to it being the exponent of the chip thickness. As the radial width of cut is being identified for the model and thus available, the above stated effect is also considered in the wear model. This results into two wear models (Model 1 without adjustment for the width of cut, Model 2 with adjustment) that shall be compared in Chapter 4. As the progression of the relative area increases similar to an S-shape, a Sigmoid function is used as the basis for both models. To increase flexibility in the model parameters, an arcus tangent function was chosen, as presented in (1):

$$
V B=A+B * \arctan \left(\frac{r}{c}-D\right)
$$

where: $A, B, C, D$ : model parameters, $r$ : relative increase of the polar figure. 
The model consists of two parts. The first is expressed as $A$ and describes the model offset. It can be interpreted as the mean value for the tool wear. The second part describes the tool wear itself, and used a modified arcus tangent function. Since the arcus tangent function ranges between -1 and $1, B$ scales the function to the required value. This parameter is hence also dependent on the engagement situation. The arcus tangent function is usually defined between $-\pi$ and $\pi$. In order to shift it to the required range of $V B$, the parameters $C$ and $D$ are used. These parameters can be calculated to set the function within the required region according to (2) and (3):

$$
\begin{aligned}
& C=\frac{r_{\text {max }}-r_{\text {min }}}{2 \pi} \\
& D=\frac{2 \pi * r_{\text {min }}}{r_{\text {max }}-r_{\min }}
\end{aligned}
$$

where: $C, D$ : model parameters, $r_{\min }$ : minimum area ratio, $r_{\max }$ : maximum area ratio.

The model parameters $A$ and $B$ were determined with an optimization algorithm implemented in MATLAB, using the "fmincon function". Table 1 shows the model parameters obtained by three sets of measurement.

Table 1. Model parameters

\begin{tabular}{|c|c|c|c|}
\hline A & B & C & D \\
\hline 81.89 & 36.9 & 0.14 & 8.64 \\
\hline 93.21 & 38.75 & 0.13 & 10.02 \\
\hline 93.87 & 40.11 & 0.14 & 9.17 \\
\hline 99.93 & 42.88 & 0.13 & 10.3 \\
\hline 97.29 & 43.24 & 0.12 & 10.46 \\
\hline
\end{tabular}

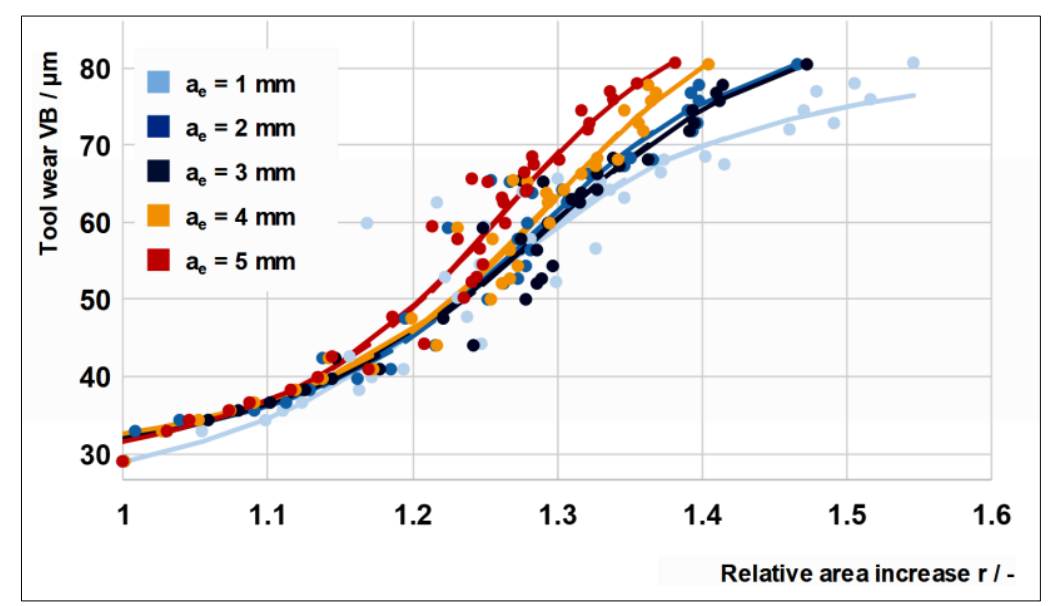

Fig. 6. Model 2

Figure 6 depicts the result of model 2. The points indicate the measured tool wear, the lines indicate the progression of the tool wear model. While very strong accordance is reached for lower tool wear values and again for higher tool wear values, all five curves show a stronger error for tool wear values between $40 \mu \mathrm{m}$ and $70 \mu \mathrm{m}$. This is also the area of the strongest curvature of the arctan function, hence of the lowest prediction accuracy. 


\section{MODEL VALIDATION}

Due to the dependency of the force-increasing effect of tool wear on the chip thickness and hence the width of cut, two models were trained and compared. Model 1 uses all data points available for all widths of cut, while model 2 uses the identification method of the engagement conditions described in Chapter 2 to determine the right model, and then estimates the tool wear amount. Both models are validated with another set of tool wear data, gained from a repetition of the three experiments described in Chapter 3. Figure 7 shows a comparison of the real, measured flank wear with the estimated flank wear from either model 1 (left) or model 2 (right).
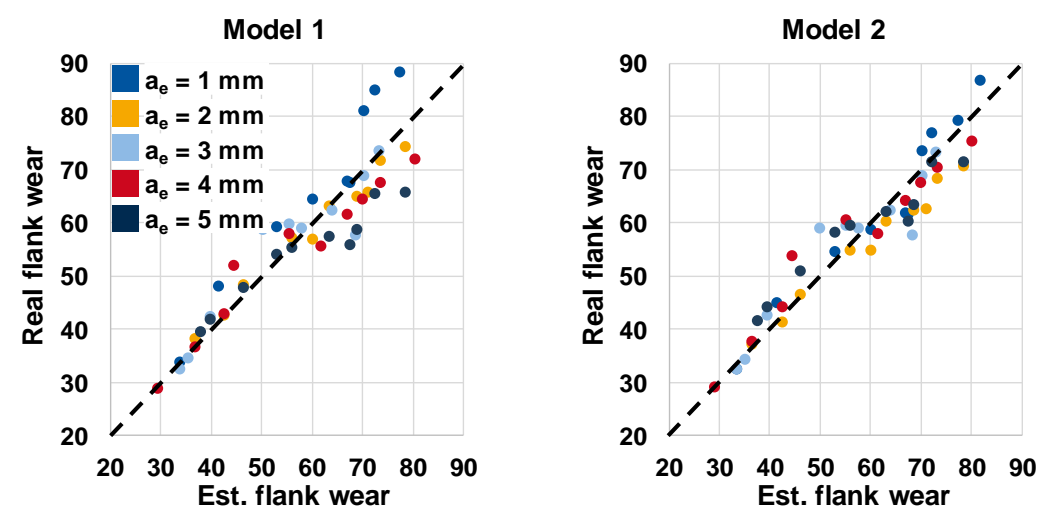

Fig. 7. Model comparison

For each measurement point, its real flank wear value is shown at the ordinate and its respective estimated flank wear value at the abscissa. A perfect estimation would hence lie on the black dotted line (Real flank wear = estimated flank wear). The estimation of the engagement situation was used as a classification, essentially classifying each polar figure into five classes according to $a_{e} \in[1,2,3,4,5]$. While the estimation of the engagement conditions is necessary to identify the reference value for the polar figure area, it can also be used to improve the model accuracy by adjusting the model depending on the engagement conditions. While both models perform equally well for lower tool wear values up to approximately $50 \mu \mathrm{m}$, model 1 shows a larger error for larger tool wear values. This can be attributed to the dependency of the tool wear effect on the chip thickness and the stronger effect for larger tool wear values. In model 2, the error stays equally low for all tool wear values.

\section{CONCLUSION AND OUTLOOK}

In order to measure tool wear in small batch and single item production, different approaches are shown in research and industry. This research paper shows an approach of identifying the tool wear in combination with an identification of the engagement 
conditions. An identification algorithm for the width of cut was shown in accordance to [26]. Furthermore, two different tool wear models were developed, one universal model for all widths of cut, and one that distinguishes between the different widths of cut. The model was trained using data from end milling processes with different cutting speeds, but constant feed rates. Both models were validated at another set of similar tool wear experiments. While both models were able to predict the engagement conditions sufficiently accurate and identify the flank wear value with an error of less than $10 \%$, the second model, which included the information of the width of cut, showed significantly better results especially for larger amounts of tool wear.

In further research, two main improvements need to be undertaken: While the influence of the width of cut was implemented, there is no analysis about the influence of the depths of cut, and also no identification of it. Therefore, a new identification method that identifies both aspects of the engagement conditions is required. As a second improvement, the tool wear model needs to be refined, extended to more different materials and proven under different cutting conditions, especially different feed rates and depths of cut.

\section{ACKNOWLEDGEMENTS}

This research was funded by the AiF - ZIM project "Modellentwicklung zur Berücksichtigung von Prozess-, Maschinen und Werkzeugeinflüssen bei der Verschleißberechnung und -prognose für spanabhebende Werkzeuge” (ZF4040910PO7).

\section{REFERENCES}

[1] DIN8580:2003-09: Manufacturing Processes - Terms and Definitions, Division, https://dx.doi.org/10.31030/ 9500683.

[2] KLOCKE F., 2011, Manufacturing Processes, Berlin, Heidelberg, New York, Springer.

[3] AUGSPURGER T., 2019, Thermal Analysis of the Milling Process, Dissertation RWTH, ISBN: 978-3-86359676-7.

[4] BAYRAMOGLU M., DUNGEL Ü., 1998, A Systematic Investigation on the Use of Force Ratios in Tool Condition Monitoring for Turning Operations, Trans. Inst. Meas. Control, 20/2, 92-97.

[5] DIMLA D.E., 2000, Sensor Signals for Tool Wear Monitoring in Metal Cutting Operations - A Review of Methods, Int. J. Mach. Tool Manuf., 40/8, 1073-1098.

[6] KETTELER G., 1996, Prozessüberwachung mit Acoustic-Emission beim Messerkopfstirnfräsen, Dissertation, RWTH Aachen.

[7] YOHANNES B., 2013, Industrielle Prozessüberwachung für die Kleinserienfertigung, Berichte aus dem IFW, 03, PZH Verlag.

[8] KAUPP M., 2014, Ein Verfahren zur automatischen erzeugung intelligenter prozessüberwachungssysteme, Stuttgart, Fraunhofer Verlag.

[9] KAEVER M., 2004, Steuerungsintegrierte fertigungsprozess-überwachung bei spanender Bearbeitung, Dissertation, RWTH Aachen, Shaker Verlag.

[10] GHANI J.A., 2009, New Regression Model and I-Kaz Method for Online Cutting Tool Wear Monitoring, Int. J. of Mechanical, Aerospace, Industrial, Mechatronic and Manufacturing Engineering, 3, 1507-1512.

[11] GHANI J.A., 2013, The Application of I-Kaz-Based Method for Tool Wear Monitoring Using Cutting Force Signal, Procedia Engineering, 68, 461-468.

[12] AHMAD M.A.F., NUAWI M.Z., ABDULlAHA S., WAHIDA Z., KARIMB Z., DIRHAMSYAH M., 2015, Development of Tool Wear Machining Monitoring Using Novel Statistical Analysis Method, I-Kaz, Procedia Engineering, 101, 335-362.

[13] KASIM N.A., 2019, Cutting Power Wear Progression Index via Signal Element Variance, Journal of Mechanical Engineering and Sciences, 13, 4596-4612. 
[14] FUSSEL B., 2015, Real-Time Tool Wear Monitoring in Milling Using a Cutting Condition Independent Method, International Journal of Machine Tools \& Manufacture, 89, 1-13.

[15] CUI Y., 2009, Tool Wear Monitoring for Milling by Tracking Cutting Force Model Coefficients, Proceedings of the North American Manufacturing, Research Institution of SME, 37.

[16] ZHOU Y., XUE W., 2018, A Multisensor Fusion Method for Tool Condition Monitoring in Milling, Sensors, 18, 3866-3878.

[17] DENKENA B., 2015, Die vernetzte Produktion - Forschungsergebnisse für die praxis, Final report of the SFB 653 collaborate research center, PZH Verlag Hannover, ISBN: 978-3-95900-045-1.

[18] SCHMIDT C., 2011, Einflussgrößensensitive simulation und überwachung von fräsprozessen, Berichte aus dem IFW 01/2011, PZH Verlag.

[19] LITWINSKI K.M., 2011, Sensorisches spannsystem zur überwachung von zerspanprozessen in der einzelteilfertigung, Berichte aus dem IFW, 02/2011, PZH Verlag.

[20] SHENG H., 2012, Model-Based Tool Condition Monitoring for Ball-Nose End Milling, PhD-Thesis, National University of Singapore.

[21] ALTINTAS Y., YELLOWLEY I., 1987, The Identification of Radial Width and Axial Depth of Cut in Peripheral Milling, International Journal for Machine Tools and Manufacture, 27/3, 367-381.

[22] TARN J.H., TOMIZUKA M., 1989, On-Line Monitoring of Tool and Cutting Conditions in Milling, Journal of Engineering for Industry, 111, 206-212.

[23] KWON W.T., CHOI D., 2002, Radial Immersion Angle Estimation Using Cutting Force and Predetermined Cutting Force Ratio in Face Milling, International Journal of Machine Tools \& Manufacture, 42, 1649-1655.

[24] HWANG J.H., 2003, In-Process Estimation of Radial Immersion Ratio in Face Milling Using Cutting Force, International Journal of Advanced Manufacturing Technology, 22, 313-320.

[25] CHOI J-G., YANG M-Y., 1999, In-Process Prediction of Cutting Depths in End Milling, International Journal of Machine Tools and Manufacture, 39/5, 705-721.

[26] BERGS T., GOETZ S., 2019, Estimation of Engagement Conditions Using an ANN Pattern Recognition System on the Base of a Sensory Tool Holder, MM Science Journal, 11, DOI: 10.17973/MMSJ.2019_11_2019086.

[27] KARPUSCHEWSKI B., Sensoren zur prozessüberwachung beim spanen, Fortschritts-Berichte, 2/581, VDI Verlag, Düsseldorf, ISBN: 3-18-358102-7.

[28] KIENCKE U., 2008, Signalverarbeitung, Zeit-Frequenz-Analyse und Schätzverfahren, Oldenburg-Verlag, München. 